\title{
Análise dos principais indicadores de pobreza e desigualdade social de Mato Grosso do Sul
}

\author{
Karine Medeiros Anunciato \\ Universidade Federal de Mato Grosso (UNEMAT) \\ karine@unemat.br \\ Economista formada pela Universidade Federal de Mato Grosso (UFMT), Mestre em \\ Agricultura Tropical pela UFMT e Doutora em Economia Aplicada pela Universidade Federal \\ de Pernambuco (UFPE/PIMES) \\ Cleiton Franco \\ Universidade do Estado de Mato Grosso \\ cleitonfranco@unemat.br \\ Graduado em Ciências Contábeis pela Universidade do Estado de Mato Grosso (2003), \\ Mestre em Agricultura Tropical pela UFMT e Doutorando em Economia Aplicada pela \\ Universidade Federal de Pernambuco (UFPE/PIMES)
}

\section{RESUMO}

O objetivo desse trabalho foi analisar os indicadores de pobreza e desigualdade social do estado de Mato Grosso do Sul (MS). Foram utilizados dados da Pesquisa Nacional por Amostra de Domicílios (PNAD), referente aos anos de 2001 a 2011, do Censo Demográfico de 2010 do IBGE e do Atlas do Desenvolvimento Humano no Brasil de 2013. Foram apresentados os Índices de Desenvolvimento Humano Municipal (IDHM) dos municípios, indicadores de pobreza e o Índice de GINI dos municípios do MS. Em 2010, MS apareceu com $10^{\circ}$ colocado no ranking dos estados brasileiros com IDH de 0,729. A proporção de pobres no estado de Mato Grosso do Sul foi reduzindo, chegando ao seu menor valor no ano de 2011 (19,60\%) consideravelmente menor que 2003 (44,85\%). No ano de 2010 apenas 51, dos 78 municípios de MS, apresentaram Índice de Gini maior ou igual a 0,50. Os municípios de Novo Horizonte do Sul $(0,40)$, Taquarussu $(0,42)$ e Angélica $(0,42)$, são os que apresentam menor Índice de Gini, ou seja, os que apresentam melhor distribuição de renda. No outro extremo os municípios com os piores Índice de Gini são os municípios de Japorã $(0,66)$, Paranhos $(0,64)$, Bela Vista $(0,61)$, Douradina $(0,61)$ e Porto Murtinho $(0,61)$.

Palavras chaves: Indicadores sociais, qualidade de vida, pobreza extrema.

\section{ABSTRACT}

The objective of this study was to analyze the indicators of poverty and social inequality in the state of Mato Grosso do Sul (MS). The used by Pesquisa Nacional por Amostra de Domicílios (PNAD) for the years 2001 to 2011, the IBGE's 2010 Demographic Census and Atlas of Human Development in Brazil in 2013 were presented the Municipal Human Development Index (IDHM) of municipalities, poverty indicators and the GINI Index of the municipalities of MS. In 2010, MS appeared in 10th place in the ranking of Brazilian states with an IHD of 0.729. The proportion of poor in the state of Mato Grosso do Sul has been reducing, reaching its lowest level in 2011 (19.60\%) considerably less than in 2003 (44.85\%). In 2010 only 51 of the 78 municipalities of MS, presented Gini index greater than or equal to 0.50. The municipalities of New South Horizonte (0.40), Taquarussu (0.42) and 
Angelica (0.42), are those with lower Gini index, ie, those with better income distribution. At the other end the municipalities with the worst Gini Index are the municipalities of Japorã (0.66) Paranhos (0.64), Bela Vista (0.61), Douradina (0.61) and Porto Murtinho (0.61).

Key words: social indicators, quality of life, extreme poverty.

\section{INTRODUÇÃO}

Fundado em outubro de 1977, e instalado em janeiro de 1979, pelo presidente, Ernesto Geisel, após o desmembramento do território do Mato Grosso surge um novo estado no Brasil: Mato Grosso do Sul. Com atualmente 78 municípios, cuja a capital é Campo Grande, possui uma superfície de $357.145,532 \mathrm{~km}^{2}$, participando com 22,2\% da superfície da região Centro-Oeste e 4,2\% da área territorial brasileira (de $8.514 .876,6 \mathrm{~km}^{2}$ ), sendo ligeiramente maior que a Alemanha (IBGE, 2013)

Está localizado ao sul da região Centro-Oeste. Tem como limites os estados de Goiás a nordeste, Minas Gerais a leste, Mato Grosso (norte), Paraná (sul) e São Paulo (sudeste), além da Bolívia (oeste) e o Paraguai (oeste e sul). Segundo o Instituto Brasileiro de Geografia e Estatística (IBGE), Mato Grosso do Sul possui população estimada em cerca de 2.587.267 milhões em 2013, com densidade demográfica de 6,86 (hab/ $/ \mathrm{km}^{2}$ ), o estado registra atualmente expectativa de vida ao nascer de 75,33 anos.

Figura 1- Mapa de Mato Grosso do Sul

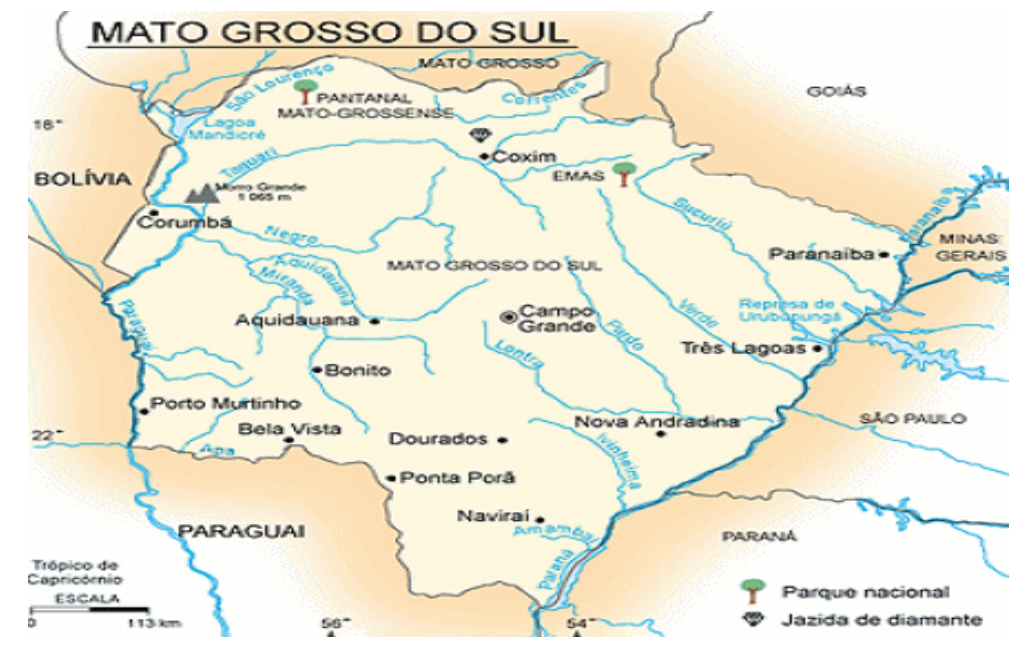

Fonte: Google Imagens

Economicamente a vocação do Mato Grosso do Sul é a agropecuária moderna, com maior rebanho bovino do país. Além disso, sustenta atividades do agronegócio que opera com qualidade mundial. Atualmente o estado apresenta elevados índices de produtividade 
agrícola, graças à combinação de solo, clima, disponibilidade de água e tecnologia (AVANÇA BRASIL, 2013).

Considerado um dos estados de maior crescimento econômico do Centro-Oeste desde o início da década de 1990, o Mato Grosso do Sul ainda possui desafios no combate à pobreza e a desigualdade social. Dessa forma, o objetivo deste trabalho é apresentar os principais indicadores sociais do estado de Mato Grosso do Sul. Para tanto, buscou-se conceituar a qualidade de vida nos dias atuais, bem como a importância de indicadores e suas formas de mensuração. Buscou-se também, caracterizar a população do MS, destacando características como gênero e raça, explicitando também o Índice de Desenvolvimento Humano Municipal (IDHM), indicadores de pobreza e o Índice de GINI dos municípios do estado de Mato Grosso do Sul.

\section{Qualidade de vida e Desenvolvimento Humano}

Historicamente o termo qualidade de vida foi utilizado na plataforma política como recomendação para o sucesso administrativo de gestores públicos, complementando corrente essencialmente economicista da época, que analisava o crescimento econômico das sociedades somente através da evolução Produto Interno Bruto (PIB) (SANTOS; MARTINS, 2002). O termo se popularizou em 1960, onde registros apontam o mesmo sendo utilizado em discursos presidenciais abordando o interesse das pessoas por uma "vida boa" ou "vida de qualidade". Além disso, os discursos da época abordavam o compromisso da sociedade em assegurar às pessoas, estruturas sociais mínimas que lhes permitissem perseguir sua felicidade (DAY; JANKEY, 1996 apud PEREIRA; TEIXEIRA e SANTOS, 2012).

Na década de 80 com a preocupação de iniciar novas formas de regras e regulamentos ambientais, surgem as análises de qualidade de vida urbana (QVU), que recebeu maior atenção dentro da ciência social ambiental (WEINBERG, 1998). Além disso, QVU tornouse um foco importante para os planejadores, agências de financiamento, e as comunidades locais (STEINBERG, 2000).

A partir da década de 1990, a discussão a discussão ganhou o âmbito acadêmico internacional, em razão das preocupações mundiais com as consequências socioambientais do acelerado processo de urbanização. A partir de então o conceito de qualidade de vida urbana passou a se situar entre o de qualidade de vida e o de qualidade ambiental de forma 
que a qualidade de vida urbana torna-se elemento chave da qualidade ambiental (NAHAS et al., 2006).

Segundo o WHOQOL Group (1996), qualidade de vida é definida pela Organização Mundial da Saúde (OMS) como: "a percepção do indivíduo de sua posição na vida no contexto da cultura e sistema de valores nos quais vive e em relação aos seus objetivos, expectativas, padrões e preocupações". Nessa visão, o que a OMS sugere que é que a qualidade de vida reflete a percepção dos indivíduos de que suas necessidades estão sendo satisfeitas ou, ainda, que lhes estão sendo negadas oportunidades de alcançar a felicidade e a auto-realização, com independência de seu estado de saúde físico ou das condições sociais e econômicas.

De acordo com Minayo et al. (2000, p.10), qualidade de vida:

É uma noção eminentemente humana, que tem sido aproximada ao grau de satisfação encontrado na vida familiar, amorosa, social e ambiental e à própria estética existencial. Pressupõe a capacidade de efetuar uma síntese cultural de todos os elementos que determinada sociedade considera seu padrão de conforto e bemestar. O termo abrange muitos significados, que refletem conhecimentos, experiências e valores de indivíduos e coletividades que a ele se reportam em variadas épocas, espaços e histórias diferentes, sendo, portanto, uma construção social com a marca da relatividade cultural.

Os autores Day e Jankey (1996, apud PEREIRA; TEIXEIRA e SANTOS, 2012) classificam os estudos sobre qualidade de vida de acordo com quatro abordagens gerais: econômica, psicológica, biomédica e geral ou holística. A abordagem socioeconômica tem os indicadores sociais como principal elemento. Contudo os indicadores sociais ou objetivos servem somente como indicadores indiretos de qualidade de vida.

Isso porque a qualidade de vida deveria ser analisada considerando a vida atual e um padrão a ser comparado. Essa abordagem combinou múltiplos aspectos de seis dimensões de análise:

\begin{abstract}
A primeira refere-se a objetivo-realização e se relaciona às questões entre o que se tem e o que se quer ter. Um segundo aspecto da teoria analisa o que os povos realmente consideram ser o seu ideal real de vida. Um terceiro tipo envolve a relação percebida entre as circunstâncias atuais e o que se espera se tornar. Um quarto tipo inclui a relação percebida entre qualidade de vida atual e a melhor qualidade de vida que já se teve no passado. Um quinto sugere que uma questão importante a ser analisada é o que é possuído por uma pessoa e pelo grupo de referência e uma sexta considera importante buscar esclarecer o quão bom é o ajuste da pessoa no ambiente em que se está inserido. (DAY E JANKEY, 1996 apud PEREIRA; TEIXEIRA e SANTOS, 2012)
\end{abstract}

Percebe-se que não existir conceito único e definitivo sobre qualidade de vida. Isso porque trata-se de conceito para o qual até mesmo uma definição operacional é difícil de ser 
elaborada. Entretanto pode-se estabelecer elementos para pensar nessa noção enquanto fruto de indicadores ou esferas objetivas (sociais) e subjetivas, a partir da percepção que os sujeitos constroem em seu meio (BARBOSA, 1998).

Dessa forma pesquisadores buscam pontos de vista objetivos, com análises ou compreensão da realidade pautada em elementos quantificáveis e concretos, que podem ser transformados pela ação humana. O estudo e análise desses elementos consideram fatores importantes como moradia, acesso à saúde, alimentação, saneamento básico, emprego, educação, transporte, ou seja, necessidades de garantia de sobrevivência próprias da sociedade contemporânea (ALMEIDA, 2012).

Segundo Almeida (2012) busca-se caracterizar a análise em qualidade de vida com dados qualitativos e quantitativos e que permitam traçar perfis de indivíduos ou grupos em relação ao seu acesso a bens e serviços. Esses dados são gerados com base em informações globais dos grupos estudados. A partir destes dados, são traçados índices estatísticos de referência sobre posições socioeconômicas de populações, cidades e regiões, bem como comparações entre objetos diferentes. Torna-se possível, com esse tipo de tratamento e análise, estabelecer quadros de perfis socioeconômicos para ações voltadas à melhoria da qualidade de vida dos sujeitos envolvidos.

Atualmente considerar somente o Produto Interno Bruto (PIB) per capita como medida de qualidade de vida pode ser um parâmetro problemático, isso porque em muitos contextos socioeconômicos, as trocas ou a obtenção do bem-estar não se dão apenas através do dinheiro. Na verdade a qualidade de vida pode é traduzida pelo acesso do indivíduo e das famílias, em conjunto de pré-condições, tais como habitação sadia, acesso a alimentos, a serviços de saúde, educação, saneamento etc. (ROCHA, 2008).

A perspectiva deste conceito seria então muito mais ampla que a simples análise do crescimento econômico, onde é considerada apenas a geração de produção, emprego e renda para determinada sociedade. Trata-se de considerar também o desenvolvimento humano identificando a as oportunidades e capacidades dos indivíduos e não apenas sua expectativa de geração de renda (PNUD, 2013).

A renda é importante, mas como um dos meios do desenvolvimento e não como seu fim. É uma mudança de perspectiva: com o desenvolvimento humano, o foco é transferido do crescimento econômico, ou da renda, para o ser humano. Para o PNUD (1996) não existe uma ligação automática entre o crescimento econômico e o desenvolvimento humano, mas quando tais relações são forjadas através de políticas direcionadas, o crescimento econômico 
torna-se impulso eficaz para o desenvolvimento humano. Seria então quase como definir claramente que, em condições ideais, as economias existem para satisfazer as necessidades humanas e não o inverso.

\section{Indicadores Sociais}

Segundo Mitchell (1997, apud MARZALL, 2000) um indicador é uma ferramenta que permite a obtenção de informações sobre determinada realidade. Sua principal característica é de sintetizar um conjunto complexo de informações, retendo apenas o significado essencial dos aspectos analisados.

"Indicadores são medidas da condição, dos processos, da reação ou do comportamento dos sistemas complexos que podem fornecer uma confiável síntese. As relações entre os indicadores (conjunto de indicadores) e o padrão de respostas dos sistemas pode permitir a previsão de futuras condições. As medidas devem evidenciar modificações que ocorrem em uma dada realidade principalmente as mudanças determinadas pela ação antrópica." (AUSTRALIAN DEPARTMENT OF PRIMARY INDUSTRIES AND ENERGY, 1995, apud MARZALL, 2000)

Considera-se então que os indicadores seriam medidas dos processos produtivos servindo como resumo de sistemas complexos, contribuindo para desenvolvimento de políticas que permitam evitar desastres ecológicos, dado que os principais usuários dos indicadores seria o governo, as empresas que buscam suas estratégias de sustentabilidade e os consumidores que se preocupam com as questões adversas das atividades econômicas.

As medidas devem evidenciar modificações que ocorrem em dada realidade, identificando os pontos problemáticos de determinado agroecossistema, por exemplo. Além disso, é uma forma prática de comunicar a situação de dada realidade. Segundo Borba (2009), o indicador é um estimador relacionado a um atributo, propriedade ou característica determinada, que irá fornecer informações sobre o comportamento do fenômeno ou sistema objeto do estudo.

Com relação à utilidade do indicador COLE (2002, apud Borba, 2009), tem a seguinte definição:

Para ter utilidade, um indicador deve ser confiável, representativo, comparável e rastreável, permitindo explicações das causas das mudanças em seu valor ao longo do tempo. Além disso, deve ser suficientemente simples na forma como descreve problemas mais complexos, usando definições comuns e normas que permitam comparações. 
Ainda segundo Borba (2009) como os indicadores podem ser derivados de outras variáveis, sendo importante o entendimento da relação entre os dados primários e os mesmos. Algumas das características dos indicadores de sustentabilidade a ser levadas em consideração devem apresentar, segundo Veleva e Ellenbecker (2000) são:

- Deve relacionar a poluição ambiental diretamente com o desempenho ambiental, ou seja, os indicadores devem correlacionados diretamente com o objeto de estudo;

- Devem permitir comparações entre diferentes sistemas, o que requer padronização na estimação desses indicadores;

- Simplicidade e metodologia passível de entendimento, sendo que os indicadores quantitativos são mais objetivos (com a desvantagem que podem omitir informações importantes);

- Deve-se preferir também um conjunto de indicadores ao invés de optar por somente um, evitando perder informações e fazer inferências com base em resultados viesado, além disso, um processo que conduza à seleção de indicadores inadequados conduz a sistemas com problemas.

- Ser sensível à implantação de políticas públicas;

- Os dados devem ser estar disponível, com informações precisas.

Com relação às funções dos indicadores, Hardi e Barg (1997, apud Borba, 2009), afirmam que podem ser divididos em: Indicadores sistêmicos que são baseados em referenciais técnicos e possuem a capacidade de comunicar as informações mais importantes aos tomadores de decisão; e Indicadores de performance, que fornecem informações sobre o grau de sucesso na realização das metas, sendo bastante utilizados no campo da avaliação política e no processo decisório.

Segundo Jannuzzi (2001) para a pesquisa acadêmica, o Indicador Social pode servir como elo entre modelos explicativos da Teoria Social e a evidencia empírica dos fenômenos sociais observados. Dessa forma, Jannuzzi (2001) considera que:

\begin{abstract}
Em uma perspectiva programática, o Indicador Social é urn instrumento operacional para monitoramento da realidade social, para fins de formulação e reformulação de politicas publicas. Taxas de analfabetismo, rendimento médio do trabalho, taxas de mortalidade infantil, taxas de desemprego, Índice de Gini, proporção de crianças matriculadas em escolas são, neste sentido, indicadores sociais, ao traduzir em cifras tangíveis e operacionais das varias dimensões relevantes, especificas e dinâmicas da realidade social.
\end{abstract}

Podem-se classificar os indicadores entre objetivos e subjetivos, ou entre indicadores quantitativos e qualitativos. Os indicadores objetivos (quantitativos) são construídos à partir 
das estatísticas publicas disponíveis, e se referem a ocorrências concretas ou entes empíricos da realidade social. Como exemplos de indicadores objetivos têm-se a taxa de desemprego, a taxa de evasão escolar ou o risco de acidentes de trabalho. Já os indicadores subjetivos (qualitativos), por outro lado, são medidas construídas a partir da avaliação dos indivíduos ou especialistas com relação a diferentes aspectos da realidade, geralmente identificadas em pesquisas de opinião pública ou grupos de discussão (JANNUZZI, 2001).

Estas diferenças conceituais entre indicadores quantitativos e qualitativos podem gerar conclusões diferentes quando referidos a uma mesma dimensão social. Em uma investigação dos impactos sociais de programas governamentais, por exemplo, é bem possível que os indicadores objetivos reflitam alguma melhoria com relação às condições materiais de vida da população que, no entanto, não apresentem indicadores de satisfação favoráveis, quando baseados na opinião dos entrevistados.

Indicadores de impacto referente à exclusão social e sistemas de avaliação voltados às demandas dos tomadores de decisão, e anseios da sociedade são necessários para gestão das cidades. Estes indicadores contribuem no processo de monitorar as desigualdades sociais e precisam ser identificados e analisados. Este ensaio propõe abordar os principais indicadores sociais do estado de Mato Grosso do Sul, para tanto serão apresentados conceitos referentes aos indicadores e suas metodologias, e resumidamente os principais impactos destes números no estado.

\section{Metodologia}

Serão analisados os seguintes indicadores do estado de Mato Grosso do Sul:

\subsection{O Índice de Desenvolvimento Humano (IDH)}

O Índice de Desenvolvimento Humano (IDH) é uma medida importante concebida pela Organização das Nações Unidas (ONU) para avaliar a qualidade de vida e o desenvolvimento econômico de uma população. Fornecido pelo Atlas do Desenvolvimento Humano no Brasil 2013, é uma plataforma de consulta ao Índice de Desenvolvimento Humano Municipal (IDHM) de 5.565 municípios brasileiros, e a mais de 180 indicadores de população, educação, habitação, saúde, trabalho, renda e vulnerabilidade, com dados extraídos dos Censos Demográficos de 1991, 2000 e 2010. 
O índice varia de 0 (nenhum desenvolvimento humano) a 1 (desenvolvimento humano total). Segundo PNUD (2013) nações com IDH até 0,499 têm desenvolvimento humano considerado baixo; os índices entre 0,500 e 0,799 são considerados de médio desenvolvimento humano; IDH maior que 0,800 têm desenvolvimento humano considerado alto.

Para analisar as condições de núcleos sociais menores, como os municípios, é utilizado do IDH municipal (IDHM), onde são considerados os seguintes fatores, educação, longevidade e renda, conforme quadro 01.

Quadro 01 - Resumo dos fatores considerados pelo PNUD para cálculo do IDHM.

\begin{tabular}{|c|c|c|}
\hline $\begin{array}{c}\text { EDUCAÇ } \tilde{\mathbf{A O}} \\
\text { DHM-E }\end{array}$ & $\begin{array}{c}\text { LONGEVIDADE } \\
\text { IDHM-L }\end{array}$ & $\begin{array}{c}\text { RENDA } \\
\text { DHM-R }\end{array}$ \\
\hline $\begin{array}{l}\text { Considera dois indicadores, com pesos } \\
\text { diferentes: taxa de alfabetização de } \\
\text { pessoas acima de } 15 \text { anos de idade (com } \\
\text { peso dois) e a taxa bruta de frequência à } \\
\text { escola (com peso um). O primeiro } \\
\text { indicador é o percentual de pessoas com } \\
\text { mais de } 15 \text { anos capaz de ler e escrever } \\
\text { um bilhete simples (ou seja, adultos } \\
\text { alfabetizados). O segundo indicador é } \\
\text { resultado de uma conta simples: o } \\
\text { somatório de pessoas que frequentam os } \\
\text { cursos fundamental, secundário e } \\
\text { superior é dividido pela população na } \\
\text { faixa etária de } 7 \text { a } 22 \text { anos da localidade. }\end{array}$ & $\begin{array}{l}\text { Considera o mesmo indicador do } \\
\text { IDH de países: a esperança de } \\
\text { vida ao nascer. Esse indicador } \\
\text { mostra o número médio de anos } \\
\text { que uma pessoa nascida naquela } \\
\text { localidade no ano de referência } \\
\text { (no caso, 2000) deve viver. O } \\
\text { indicador de longevidade } \\
\text { sintetiza as condições de saúde e } \\
\text { salubridade daquele local, uma } \\
\text { vez que quanto mais mortes } \\
\text { houver nas faixas etárias mais } \\
\text { precoces, menor será a } \\
\text { expectativa de vida observada no } \\
\text { local. }\end{array}$ & $\begin{array}{l}\text { Para se chegar a esse valor } \\
\text { soma-se a renda de todos os } \\
\text { residentes e divide-se o resultado } \\
\text { pelo número de pessoas que } \\
\text { moram no município (inclusive } \\
\text { crianças ou pessoas com renda } \\
\text { igual a zero). No caso brasileiro, } \\
\text { o cálculo da renda municipal per } \\
\text { capita é feito a partir das } \\
\text { respostas ao questionário } \\
\text { expandido do Censo - um } \\
\text { questionário mais detalhado do } \\
\text { que o universal e que é aplicado } \\
\text { a uma amostra dos domicílios } \\
\text { visitados pelos recenseadores. }\end{array}$ \\
\hline
\end{tabular}

Fonte: Adaptado de PNUD (2013)

Calculados as três dimensões analisadas, IDHM-E, para educação; IDHM-L, para longevidade e IDHM-R, para renda. Para tanto, são determinados os valores de referência mínimo e máximo de cada categoria, que serão equivalentes a 0 e 1 , respectivamente, no cálculo do índice. Os sub-índices de cada município serão valores proporcionais dentro dessa escala: quanto melhor o desempenho municipal naquela dimensão, mais próximo o seu índice estará de 1. O IDHM de cada município é dado por:

$$
I D H M=\frac{(\mathrm{IDHM}-\mathrm{E}+\mathrm{IDHM}-\mathrm{L}+\mathrm{IDHM}-\mathrm{R})}{3}
$$

\subsection{Indicadores de pobreza}

Os objetivos dos indicadores de pobreza são dimensionar o contingente de pessoas em condições precárias de sobrevivência, bem como identificar variações geográficas e temporais da proporção de pobres, identificando situações que podem demandar avaliação mais aprofundada. Por oportuno os índices contribuem permitindo analisar as faixas da 
população que requerem maior atenção de políticas públicas de saúde, educação e proteção social, entre outras (BVS, 2011).

Os dados foram obtidos por:

- Pesquisa Nacional por Amostra de Domicílios (PNAD), referente aos anos de 2001 à 2011, realizada pelo IBGE.

- Censo Demográfico de 2010, realizada pelo IBGE.

- Atlas do Desenvolvimento Humano no Brasil, realizado pelo PNUD.

\subsubsection{Proporção de pobres $\left(P_{0}\right)$ - Poverty Headcount}

Segundo Centro de Políticas Sociais da Fundação Getúlio Vargas (2013) representa o percentual da população residente com renda familiar mensal per capita de até meio salário mínimo, em determinado espaço geográfico, no ano considerado.

É dado pela seguinte equação:

$P_{o}=\left[\frac{\text { População residente com renda familiar mensal per capita de até meio salário mínimo }}{\text { População total residente }}\right] \times 100$

\subsubsection{Gap de Pobreza $\left(P_{1}\right)$ - Poverty Gap}

Pode ser interpretado como indicador do déficit de pobreza, ou seja, os recursos necessários para elevar a renda de todos os pobres ao nível da linha de pobreza, uma vez que mede a intensidade de pobreza para o conjunto da população pobre através do calculo do desvio médio entre a renda dos pobres e o valor da linha de pobreza (NEDER, 2013).

$$
P_{1}=\frac{1}{n} \sum_{i=1}^{q} \frac{z-y_{i}}{z}
$$

Onde: $q$ é o número de pobres, pessoas cuja renda per capita domiciliar é menor que a linha de pobreza, ou seja, de até meio salário mínimo; n é o tamanho da população; $z$ é a linha de pobreza e $y_{i}$ e a renda per capita domiciliar da i-ésima pessoa. $\mathrm{O}$ hiato médio em relação a linha de pobreza é calculado somando quanto falta para cada individuo atingir a linha de pobreza, seria então, o menor custo financeiro para erradicação da pobreza. 


\subsubsection{Gap de Pobreza elevado ao quadrado $\left(P_{2}\right)$ - Squared Poverty Gap}

O terceiro indicador de pobreza $P_{2}$ é geralmente descrito como indicador de severidade da pobreza. Em sua construção utiliza-se um peso maior para as pessoas mais pobres (o "gap de pobreza" e ponderado por si mesmo) levando em conta a desigualdade de renda entre os pobres.

$$
P_{1}=\frac{1}{n} \sum_{i=1}^{q}\left[\frac{z-y_{i}}{z}\right]^{2}
$$

Como complemento será analisado o rendimento médio domiciliar per capita do estado nos anos de 2001 a 2011, segundo a PNAD.

\subsection{O Índice de GINI}

Segundo Neder (2013), é o índice de distribuição de renda mais conhecido e de maior aplicação. O Gini é uma medida de desigualdade desenvolvida pelo estatístico italiano Corrado Gini, e é comumente utilizado para calcular a desigualdade de distribuição de renda, mas pode ser usada também para qualquer distribuição, como concentração de terra, riqueza entre outras (IPECE, 2010).

Consiste em um número entre 0 e 1 , onde 0 corresponde à completa igualdade de renda, onde todos têm a mesma renda e 1 corresponde à completa desigualdade, onde uma pessoa tem toda a renda, e as demais nada têm. Dessa forma quanto mais o índice tende a zero, melhor será a distribuição de renda, quanto mais próximo de um, pior a distribuição e a desigualdade.

Seguindo a metodologia de Costa (2010) e IPECE (2010), considerando variável aleatória discreta $X_{i}=(i=1, \ldots, n)$, cujos valores estão em ordem crescente, $X_{1} \leq X_{2} \leq$ $X_{3} \leq \cdots \leq X_{n-1} \leq X_{n}$. Supondo que os valores de $X$ sejam igualmente prováveis.

A proporção acumulada do número de elementos até o i-ésimo é:

$$
P_{i}=\frac{i}{n}(i, \ldots, n)
$$

A correspondente acumulada de X, até o i-ésimo elemento é:

$$
\phi_{i}=\frac{\sum_{j=1}^{i} X_{j}}{\sum_{j=1}^{n} X_{j}}=\frac{1}{n \mu} \sum_{j=1}^{i} X_{j} \text {, uma vez que } \sum_{j=1}^{n} X_{j}=n \mu
$$


Assim, se $X$ representa a renda individual e se $X_{i}<X_{i+1}, \phi_{i}$ representa a fração da renda total, apropriada pelos indivíduos com renda inferior ou igual a $X_{i}$. Com as equações (5) e (6) definem as coordenadas $\left(\rho_{i}, \phi_{i}\right), \operatorname{com} i=1 \ldots n$, pontos de $n$ da curva de Lorenz.

Calculando o índice de Gini para os valores discretos, segundo IPECE (2010), seja $\beta$ a área entre a curva de Lorenz e o eixo das abscissas. Assim:

$$
\alpha+\beta=0,5 \text {, ou } \alpha=0,5-\beta
$$

Como por definição o coeficiente de Gini é uma relação entre a área da desigualdade, indicada por $\alpha$ e a área do triângulo. Tem-se: $G=\frac{\alpha}{0,5}=2 \alpha$

Substituindo (8) em (7), tem-se: $G=1-2 \beta$

Observa-se que a área $\beta$ pode ser obtida somando a área de $n$ trapézios. No caso do i-ésimo trapézio, tem-se a área $\delta_{i}$ sendo dada por:

$$
\delta_{i}=\frac{1}{2 n}\left(\phi_{i-1}+\phi_{i}\right)
$$

\section{Gráfico 1 - A poligonal de Lorenz no caso de uma distribuição discreta.}

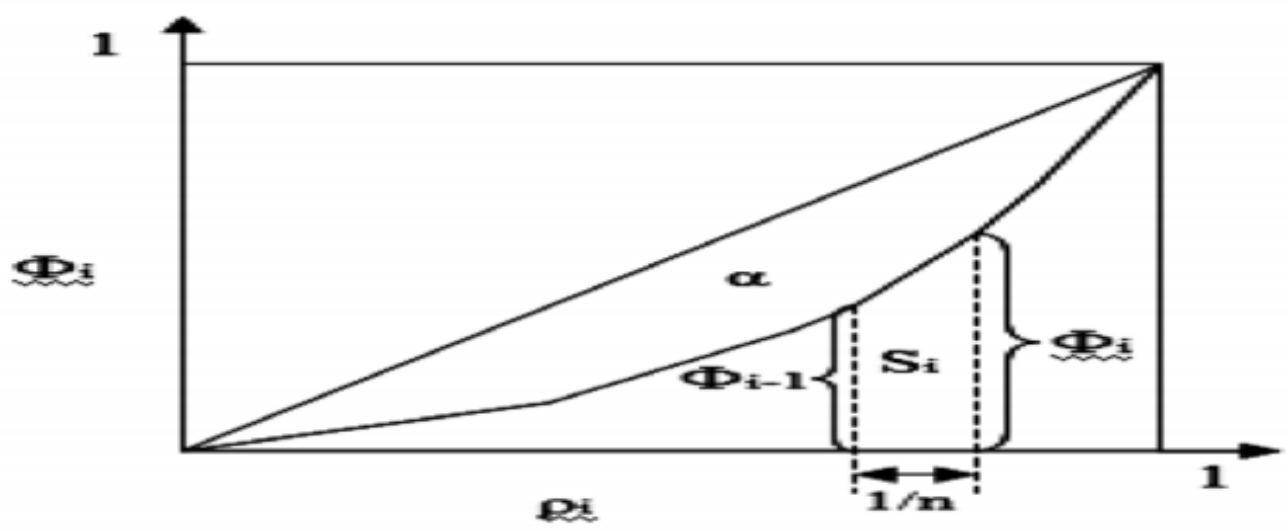

Fonte: IPECE, 2010

Descartando o primeiro triângulo, ou seja, fazendo $\phi_{0}=0$, tem-se o índice de Gini:

$$
G=1-\frac{1}{n} \sum_{i=1}^{n}\left(\phi_{i-1}+\phi_{i}\right)
$$

\section{Indicadores Sociais de Mato Grosso do Sul}




\subsection{Características gerais da população}

Conforme dados da Pesquisa Nacional por Amostra de Domicílios (PNAD), o estado totaliza 2.587.267 milhões em 2013, distribuídos em 78 municípios, desses, somente 23 possuem população superior a 20 mil habitantes. Composto por grandes propriedades possui áreas com vazios populacionais, resultando baixa densidade demográfica, que atualmente é de aproximadamente 6,8 hab./ $/ \mathrm{km}^{2}$. Com relação ao gênero a população é bem distribuída entre homens e mulheres, mas em 2011 as mulheres apresentam ligeira maioria da população $51 \%$, conforme Tabela 01.

Tabela 01 - Percentual da população, por sexo, em Mato Grosso do Sul de 2001 a 2011.

\begin{tabular}{ccccccccccc}
\hline Gênero & $2001(\%)$ & $2002(\%)$ & $2003(\%)$ & $2004(\%)$ & $2005(\%)$ & $2006(\%)$ & $2007(\%)$ & $2008(\%)$ & $2009(\%)$ & $2011(\%)$ \\
\hline Homem & 42 & 44 & 44 & 44 & 45 & 47 & 47 & 47 & 48 & 49 \\
Mulher & 44 & 43 & 45 & 46 & 47 & 47 & 48 & 49 & 49 & 51 \\
\hline
\end{tabular}

Fonte: IBGE, Pesquisa Nacional por Amostra de Domicílios (PNAD)

A população de Mato Grosso do Sul tem crescido a altos níveis desde o ano 2001, contudo neste ano 73\% da população possuía menos de 39 anos, mas em 2011 esse número foi reduzido para $65 \%$, ou seja, MS ainda possui população relativamente jovem, mas tem envelhecido ao longo dos anos. O grande desafio para grande população de jovens em determinada região são os acessos à educação e a geração de postos de trabalhos suprir as necessidades de todos.

Segundo Martins (2003), o aumento da população no MS não se deve somente a alta taxa de natalidade no estado, mas à grande quantidade de migrantes de outros estados. No ano 2000 a taxa de fecundidade no estado era de 2,4 por mulher, décima menor no Brasil, contudo no ano de 2005 cerca de 30,2\% da população residente no MS não era natural deste estado.

Com relação à raça (Tabela 02), percebe-se ao longo dos anos redução na população negra e indígena, existindo no MS grande concentração de pessoas pardas, em razão da junção de ameríndios, imigrantes paraguaios e índios guaranis (MARTINS, 2003). 
Tabela 02 - Percentual da população, por raça, em Mato Grosso do Sul de 2001 a 2011.

\begin{tabular}{cccccccc}
\hline ANO DE & \multicolumn{7}{c}{ RAÇA (\%) } \\
\cline { 2 - 8 } REFERÊNCIA & Indígena & Branca & Preta & Amarela & Parda & S.D.* & Total \\
\hline 2001 & 1,04 & 52 & 7 & 0,95 & 39 & 0,01 & 100 \\
2002 & 0,82 & 50 & 5 & 0,82 & 43 & - & 100 \\
2003 & 0,84 & 49 & 5 & 0,64 & 45 & - & 100 \\
2004 & 0,97 & 49 & 5 & 1,27 & 43 & 0,76 & 100 \\
2005 & 0,86 & 51 & 5 & 0,88 & 42 & 0,26 & 100 \\
2006 & 0,48 & 51 & 5 & 1,16 & 42 & - & 100 \\
2007 & 0,59 & 47 & 4 & 1,09 & 47 & 0,32 & 100 \\
2008 & 0,22 & 48 & 4 & 0,44 & 47 & 0,34 & 100 \\
2009 & 0,53 & 52 & 3 & 1,01 & 43 & 0,46 & 100 \\
2011 & 0,5 & 53 & 3 & 0,9 & 43 & - & 100 \\
\hline
\end{tabular}

Fonte: IBGE, Pesquisa Nacional por Amostra de Domicílios (PNAD)

Apesar de apresentar no inicio da colonização grandes grupos indígenas, atualmente, a maioria das comunidades indígenas sul-matogrossenses vive em áreas bem reduzidas. Mesmo com o aumento na população indígena de 41\% entre os anos de 2001 e 2011, essa população dilui-se entre a população marginalizada das maiores cidades do Estado, tais como Dourados, Campo Grande, Aquidauana e Miranda.

\subsection{IDHM}

Observa-se na verdade certa evolução no que diz respeito ao IDH de Mato Grosso do Sul (MS), isto porque em 1991 apesar de ocupar a $8^{\circ}$ posição no ranking nacional apresentava índice considerado muito baixo, de apenas 0,488. Esse índice foi melhorado em 2000, com valor de 0,613, considerado de médio desenvolvimento humano, apesar de cair para $10^{a}$ posição nacional. No mais recente IDH dos estados, o de 2010, Mato Grosso do Sul permanece como $10^{\circ}$ colocado no ranking dos estados brasileiros com IDH de 0,729, perdendo para estados vizinhos como Distrito Federal $(0,824)$ e São Paulo $(0,783)$, superando apenas seu vizinho mais próximo Mato Grosso $(0,725)$, mas já sendo considerado estado com alto desenvolvimento humano.

Com relação ao IDHM (demonstrado na Tabela 03) no ano de 2010, os cinco primeiros municípios apresentam IDHM maior que o do estado de MS, são eles: sua capital Campo Grande (0,784), Chapadão do Sul $(0,754)$, Dourados $(0,747)$, Três Lagoas $(0,744)$ e Maracaju (0,736).

Com relação às dimensões que compõem o IDH do estado em 2010 são: IDHM-R é de 0,740, IDHM-E é de 0,629 e o IDHM-L é de 0,833. O município que mais se destaca com 
relação à educação e renda é Campo Grande, com índices de 0,724 e 0,790 respectivamente. Contudo com relação a longevidade (saúde) o município de Chapadão do Sul destaca-se com índice de 0,850 .

Tabela 03 - Os dez melhores e piores IDHM de Mato Grosso do Sul em 2010

\begin{tabular}{clcccc}
\hline Posição & \multicolumn{1}{c}{ MUNICÍPIOS } & IDHM & IDHM-R & IDHM -L & IDHM-E \\
\hline $1^{\circ}$ & Campo Grande & 0.784 & 0.790 & 0.844 & 0.724 \\
$2^{\circ}$ & Chapadão do Sul & 0.754 & 0.758 & 0.850 & 0.665 \\
$3^{\circ}$ & Dourados & 0.747 & 0.753 & 0.843 & 0.657 \\
$4^{\circ}$ & Três Lagoas & 0.744 & 0.752 & 0.849 & 0.645 \\
$5^{\circ}$ & Maracaju & 0.736 & 0.744 & 0.873 & 0.613 \\
$6^{\circ}$ & São Gabriel do Oeste & 0.729 & 0.751 & 0.850 & 0.608 \\
$7^{\circ}$ & Cassilândia & 0.727 & 0.756 & 0.811 & 0.627 \\
$8^{\circ}$ & Paranaíba & 0.721 & 0.727 & 0.823 & 0.627 \\
$9^{\circ}$ & Nova Andradina & 0.721 & 0.716 & 0.850 & 0.616 \\
$1^{\circ}$ & Glória de Dourados & 0.721 & 0.705 & 0.822 & 0.648 \\
$\ldots$ & .. & $\ldots$ & $\ldots$ & $\ldots$ & $\ldots$ \\
$70^{\circ}$ & Aral Moreira & 0.633 & 0.628 & 0.798 & 0.507 \\
$71^{\circ}$ & Miranda & 0.632 & 0.638 & 0.782 & 0.507 \\
$72^{\circ}$ & Juti & 0.623 & 0.646 & 0.770 & 0.485 \\
$73^{\circ}$ & Itaquiraí & 0.620 & 0.645 & 0.772 & 0.479 \\
$74^{\circ}$ & Sete Quedas & 0.614 & 0.660 & 0.778 & 0.450 \\
$75^{\circ}$ & Tacuru & 0.593 & 0.615 & 0.782 & 0.434 \\
$76^{\circ}$ & Coronel Sapucaia & 0.589 & 0.607 & 0.806 & 0.417 \\
$77^{\circ}$ & Paranhos & 0.588 & 0.566 & 0.811 & 0.444 \\
$78^{\circ}$ & Japorã & 0.526 & 0.547 & 0.791 & 0.337 \\
\hline
\end{tabular}

Fonte: Atlas do Desenvolvimento Humano no Brasil, 2013.

Por oportuno, ainda analisando os IDHM, os piores resultados alcançados em MS, possuem faixas de desenvolvimento humano consideradas baixas, ou seja, situadas entre 0,500 e 0,599. Nenhum município de MS foi considerado com faixas de desenvolvimento humano muito baixo, apesar de que na dimensão da educação muitos municípios ficarem abaixo menores que 0,499 o que é considerado péssimo resultado.

Tabela 04 - Matriz de correlação entre os valores do IDHM e de seus componentes para os municípios do Estado de Mato Grosso do Sul

\begin{tabular}{|c|c|c|c|c|c|c|c|c|c|c|c|c|}
\hline & DHM 1991 & DHM 2000 & DHMI 2010 & [DHM-E 1991 & IDHM-E 2000 & DHM-E 2010 & IDHMI-L 1991 & DHHILL 2000 & DHHILL 2010 & IDHM-R 1991 & DHHI-R 2000 & DHHI-R 2010 \\
\hline IDHII 1991 & 1,0000 & & & & & & & & & & & \\
\hline IDHII 2000 & 0.8548 & 1,0000 & & & & & & & & & & \\
\hline IDHII 2010 & 0.7446 & 0.9048 & 1,0000 & & & & & & & & & \\
\hline IDHII-E 1991 & 0.9748 & 0.8265 & 0.7179 & 1,0000 & & & & & & & & \\
\hline IDHII-E 2000 & 0.8466 & 0.9588 & 0.8661 & 0.8584 & 1,0000 & & & & & & & \\
\hline IDHII-E 2010 & 0.7422 & 0.8703 & 0.9636 & 0.7431 & 0.8805 & 1,0000 & & & & & & \\
\hline IDHII-L 1991 & 0.4760 & 0.5266 & 0.4422 & 0.3563 & 0.3847 & 0.3520 & 1,0000 & & & & & \\
\hline IDHII-L 2000 & 0.5032 & 0.6586 & 0.5759 & 0.4253 & 0.4917 & 0.4513 & 0.7139 & 1,0000 & & & & \\
\hline IDHII-L 2010 & 0.4473 & 0.5731 & 0.6364 & 0.4068 & 0.4789 & 0.4744 & 0.4304 & 0.6808 & 1,0000 & & & \\
\hline IDHII-R 1991 & 0.6983 & 0.7071 & 0.6694 & 0.5751 & 0.5710 & 0.5826 & 0.5085 & 0.5514 & 0.4247 & 1,0000 & & \\
\hline IDHIII-R 2000 & 0.6823 & 0.8375 & 0.7690 & 0.6007 & 0.6714 & 0.6711 & 0.5576 & 0.6386 & 0.5320 & 0.8212 & 1,0000 & \\
\hline IDHIII-R 2010 & 0.6819 & 0.8624 & 0.9368 & 0.6270 & 0.7803 & 0.8433 & 0.4693 & 0.5743 & 0.5658 & 0.7431 & 0.8314 & 1,0000 \\
\hline
\end{tabular}


Observe, pela Tabela 04, que o IDHM 2000 e o IDHM 2010 têm uma elevada correlação $(0,9048)$ indicando que os municípios conservaram as mesmas colocações durante este período, o mesmo não ocorrendo com IDHM 1991 e o IDHM 2010 cuja correlação foi de 0,7446 , esse fator decorre do fato de MS estar em $8^{\circ}$ no ranking nacional em 1991, porém apresentar resultados ruins em seu IDH, e apesar de cair para $10^{\circ} \mathrm{em} 2000$ melhorou seu desempenho de maneira geral mantendo a posição em 2010.

Tabela 05 - Coeficientes de correlação de Spearman entre os diversos componentes do IDH e para os municípios do Estado de Mato Grosso do Sul.

\begin{tabular}{|c|c|c|c|c|c|c|c|c|}
\hline & IDHM 2000 & IDHM 2010 & IDHM-E 2000 & IDHM-E 2010 & IDHM-L 2000 & IDHM-L 2010 & IDHM-R 2000 & IDHM-R 2010 \\
\hline IDHM 1991 & 0.8621 & 0.7686 & & & & & & \\
\hline IDHM 2000 & & 0.9025 & & & & & & \\
\hline IDHM-E 1991 & & & 0.8621 & 0.7750 & & & & \\
\hline IDHM-E 2000 & & & & 0.8789 & & & & \\
\hline IDHM-L 1991 & & & & & 0.7021 & 0.3810 & & \\
\hline IDHM-L 2000 & & & & & & 0.6021 & & \\
\hline IDHM-R 1991 & & & & & & & 0.7763 & 0.7115 \\
\hline IDHM-R 2000 & & & & & & & & 0.8039 \\
\hline
\end{tabular}

Este resultado pode ser confirmado pelo resultado do coeficiente de correlação de Sperman (correlação de ordem) é de 0,9025 entre o IDHM de 2000 e 2010, e de apenas 0,8755 entre o IDHM de 1991 e 2000. Observa-se também a baixa correlação entre os IDHM de 1991 como os IDMH de 2000 e de IDHM de 2010 de educação, renda e longevidade, conforme Tabela 05.

\subsection{Indicadores de pobreza}

Para Neder (2013), identificar a proporção de pobres em determinada região é importante para subsidiar processos de planejamento, gestão e avaliação de políticas de distribuição de renda. Para Rocha (2013) a região Centro-Oeste do Brasil associada à ocupação de fronteira agrícola utilizando tecnologias modernas, se contrapõe com ao isolamento espacial dos pobres das regiões Norte e Nordeste do país, sendo que no ano de 2011 abrigava 4,9\% da população pobre do Brasil, contra 16,1\% e 40,3\% das regiões Norte e Nordeste, respectivamente.

Apesar de ser considerada região com alto desenvolvimento humano, o Centro Oeste apresenta contingente relativamente alto de pobreza extrema, 557 mil pessoas aproximadamente segundo informações do Censo Demográfico de 2010 do IBGE. Para o IBGE, a linha de extrema pobreza foi estabelecida em $\mathrm{R} \$ 70,00$ per capita considerando o rendimento nominal mensal domiciliar. 
Os dados do Censo de 2010 apontam que 104.469 pessoas estariam vivendo em situação de extrema pobreza no estado de Mato Grosso do Sul (Tabela 06), dessas aproximadamente 15.454 residem na cidade de Campo Grande, capital do estado, ocupando a $24^{\circ}$ posição entre as capitais no ranking da pobreza extrema.

Tabela 06- Quantidade e percentual de moradores de domicílios particulares permanentes, por faixas de idade, em situação de extrema pobreza, em Campo Grande, Mato Grosso do Sul (MS) e Centro-Oeste (CO), 2010.

\begin{tabular}{|c|c|c|c|c|c|}
\hline \multirow{2}{*}{ IDADE } & \multicolumn{2}{|c|}{ Campo Grande } & \multicolumn{2}{|c|}{ MS } & \multirow{2}{*}{$\begin{array}{c}\mathrm{CO} \\
\% \\
\end{array}$} \\
\hline & Quantidade & $\%$ & Quantidade & $\%$ & \\
\hline 0 a 4 & 1676 & $10,85 \%$ & 15634 & $13,02 \%$ & $11,40 \%$ \\
\hline 5 a 14 & 3536 & $22,88 \%$ & 33845 & $28,18 \%$ & $25,90 \%$ \\
\hline 15 a 17 & 882 & $5,71 \%$ & 8262 & $6,88 \%$ & $6,30 \%$ \\
\hline 18 a 19 & 482 & $3,12 \%$ & 3942 & $3,28 \%$ & $3,10 \%$ \\
\hline 20 a 39 & 3702 & $23,95 \%$ & 29261 & $24,36 \%$ & $25,90 \%$ \\
\hline 40 a 59 & 2910 & $18,83 \%$ & 20550 & $17,11 \%$ & $18,70 \%$ \\
\hline 60 ou mais & 2266 & $14,66 \%$ & 8609 & $7,17 \%$ & $8,70 \%$ \\
\hline TOTAL & 15454 & $100,00 \%$ & 120103 & $100,00 \%$ & $100 \%$ \\
\hline
\end{tabular}

Fonte: IBGE, Censo Demográfico 2010.

A faixa de idade mais afetada pela pobreza extrema no estado é a de 20 a 39 anos com $24,4 \%$ das pessoas pobres, com a mesma proporção na capital do estado. Outro ponto importante é que $48,1 \%$ da população pobre no estado tem menos de 17 anos, o que compromete o desenvolvimento individual e deixa sequelas na educação e na saúde. Segundo Kliksberg (2001):

Sob o embate da pobreza, as famílias entram em crise e muitas vezes se desarticulam. A criminalidade cresce fortemente. É quase seis vezes o que se considera internacionalmente uma criminalidade moderada. Surge intensamente ligada a fatores como o aumento do desemprego juvenil, à baixa educação, e à deterioração da família.

A proporção de pessoas que vivem na extrema pobreza tem sido reduzida ao longo dos anos, e dentre os municípios que ainda apresentam alto índice de pobreza extrema destacam-se Japorã, Dois Irmãos do Buriti e Nioaque, que nos anos de 1991, 2000 e 2010, aparecem entre os dez municípios com as mais altas proporções de pobreza extrema na população. Já os municípios de Campo Grande, Chapadão do Sul, Agua Clara, Três Lagoas e Cassilândia aparecem, nos referidos anos, como os dez municípios com as menores proporções percentuais de pobreza extrema, conforme Tabela 07. 
Tabela 07 - Os dez menores e maiores municípios, por proporção percentual de pobreza extrema*, no Mato Grosso do Sul em 1991, 2000 e 2010.

\begin{tabular}{|c|c|c|c|c|c|c|}
\hline Class. & 1991 & MUNICÍPIO & 2000 & MUNICÍPIO & 2010 & MUNICÍPIO \\
\hline $1^{\circ}$ & 3,19 & CAMPO GRANDE & 1,45 & CHAPADÃO DO SUL & 0,58 & FIGUEIRÃO \\
\hline $2^{\circ}$ & 3,73 & CHAPADÃO DO SUL & 2,05 & ÁGUA CLARA & 0,81 & BRASILÂNDIA \\
\hline $3^{\circ}$ & 4,03 & ÁGUA CLARA & 3,02 & CAMPO GRANDE & 0,88 & INOCÊNCIA \\
\hline $4^{\circ}$ & 4,90 & SONORA & 3,28 & CASSILÂNDIA & 0,93 & CHAPADÃO DO SUL \\
\hline $5^{\circ}$ & 5,44 & INOCÊNCIA & 3,57 & TRÊS LAGOAS & 0,99 & CAMPO GRANDE \\
\hline $6^{\circ}$ & 6,97 & SÃO GABRIEL DO OESTE & 3,68 & RIBAS DO RIO PARDO & 1,07 & IVINHEMA \\
\hline $7^{\circ}$ & 7,35 & PARANAÍBA & 3,77 & BRASILÂNDIA & 1,20 & CASSILÂNDIA \\
\hline $8^{\circ}$ & 7,37 & TRÊS LAGOAS & 3,89 & BANDEIRANTES & 1,27 & ÁGUA CLARA \\
\hline $9^{\circ}$ & 7,40 & CASSILÂNDIA & 4,10 & NAVIRAÍ & 1,33 & BONITO \\
\hline $10^{\circ}$ & 7,59 & FIGUEIRÃO & 4,24 & RIO VERDE DE MATO GROSSO & 1,33 & TRÊS LAGOAS \\
\hline & .. & $\cdots$ & $\cdots$ & $\cdots$ & $\cdots$ & $\cdots$ \\
\hline $69^{\circ}$ & 26,68 & MIRANDA & 17,77 & NOVO HORIZONTE DO SUL & 11,24 & DOURADINA \\
\hline $70^{\circ}$ & 27,12 & JATEÍ & 17,99 & TACURU & 11,57 & ANTÔNIO JOÃO \\
\hline $71^{\circ}$ & 27,73 & PORTO MURTINHO & 18,73 & ARAL MOREIRA & 11,89 & ARAL MOREIRA \\
\hline $72^{\circ}$ & 27,85 & DOIS IRMÃOS DO BURITI & 19,33 & COSTA RICA & 12,38 & DOIS IRMÃOS DO BURITI \\
\hline $73^{\circ}$ & 29,63 & CARACOL & 20,82 & DOURADINA & 12,47 & JUTI \\
\hline $74^{\circ}$ & 29,97 & ROCHEDO & 24,08 & DOIS IRMÃOS DO BURITI & 12,72 & NIOAQUE \\
\hline $75^{\circ}$ & 33,79 & NIOAQUE & 25,03 & NIOAQUE & 16,87 & CORONEL SAPUCAIA \\
\hline $76^{\circ}$ & 35,89 & $\begin{array}{l}\text { PARANHOS } \\
\text { NOVO HORIZONTE DO }\end{array}$ & 25,22 & JUTI & 23,07 & TACURU \\
\hline $77^{\circ}$ & 38,41 & SUL & 28,24 & JAPORÃ & 33,54 & PARANHOS \\
\hline $78^{\circ}$ & 43,14 & JAPORÃ & 37,52 & MIRANDA & 42,15 & JAPORÃ \\
\hline
\end{tabular}

* Proporção dos indivíduos com renda domiciliar per capita mensal igual ou inferior a $\mathrm{R} \$ 70,00$ mensais. Fonte: Atlas do Desenvolvimento Humano no Brasil, 2013.

Apesar dos dados comprometedores de 2010, ao analisar a evolução dos índices de pobreza Proporção de pobres $\left(\mathrm{P}_{0}\right)$, Gap de Pobreza $\left(\mathrm{P}_{1}\right)$ e Gap de Pobreza elevado ao quadrado $\left(\mathrm{P}_{2}\right)$, observa-se que no período de 2003 a 2011, a proporção de pobres no estado de Mato Grosso do Sul foi reduzindo, chegando ao seu menor valor no ano de 2011 $(19,60 \%)$ consideravelmente menor que 2003 (44,85\%), conforme Tabela 08. Não foi possível calcular a proporção de pobres $\left(P_{0}\right)$, para os anos de 2001, 2002, 2004 e 2007.

Tabela 08 - Indicadores de Proporção pobres no Estado de Mato Grosso do Sul.

\begin{tabular}{c|crcc}
\hline Ano & $\mathbf{P}_{\mathbf{0} \text { (Proporção) }}$ & $\mathbf{P}_{\mathbf{1} \text { (Razão do Hiato) }}$ & $\mathbf{P}_{\mathbf{2}}$ (Hiato Quadrático) & $\begin{array}{c}\text { Rendimento médio } \\
\text { domiciliar per capita (RS) }\end{array}$ \\
\hline 2003 & $44,85 \%$ & 0,3227 & 0,6453 & 356,25 \\
2005 & $40,83 \%$ & 0,0291 & 0,0582 & 424,78 \\
2006 & $41,13 \%$ & 0,0038 & 0,0076 & 498,52 \\
2008 & $39,25 \%$ & 0,0950 & 0,1900 & 615,55 \\
2009 & $34,48 \%$ & 0,0422 & 0,0844 & 664,64 \\
2011 & $19,60 \%$ & 0,0712 & 0,1425 & 876,97 \\
\hline
\end{tabular}

Fonte: Calculado da PNAD 
No ano de 2001 o rendimento médio domiciliar per capita foi de R\$290,74, em 2002 foi de $\mathrm{R} \$ 334,72$, em dois anos esse valor subiu apenas $\mathrm{R} \$ 44,49$, atingindo o valor de $\mathrm{R} \$$ 379,21 em 2004. Valores de outros anos são indicados na Tabela 08. A variação da elevação do rendimento médio domiciliar per capita em MS do período de 2001 a 2011, foi em média de 13\%, sendo que a menor variação foi de 2007 para 2008 (2\%), e a maior de 2009 para $2011(32 \%)$.

Ao cruzar estes valores com os dados da Pesquisa de Orçamentos Familiares (POF) de 2008-2009, com relação às despesas e rendimentos médios do estado percebe-se a renda per capita domiciliar média do estado em 2009 ( $\mathrm{R} \$ 663,64)$, dificilmente atenderia as necessidades básicas de uma família com 05 pessoas. Isto porque segundo a referida POF a despesa total média mensal familiar foi de $\mathrm{R} \$ 2.459,46$, sendo que somente os gastos médios com moradia ocupariam cerda de $28 \%$ desta renda ( $\mathrm{R} \$ 704,04)$. Outros gastos como alimentação (15\%), transporte (16\%) e saúde (6\%), também se destacam no orçamento familiar, comprometendo negativamente o indicador de rendimento médio domiciliar per capita.

Segundo Rocha (2013) escapar da pobreza absoluta não se limita a dispor de uma renda mínima de sobrevivência, mas sim de ter acesso a determinado conjunto de recursos que permita ao indivíduo funcionar adequadamente na sociedade em que vive. Apesar disso, pesquisadores utilizam a renda como ponto de parâmetro para identificar linhas de pobreza no Brasil e no mundo.

Na medida em que a renda se eleva e o consumo se diversifica, aumenta o valor do parâmetro usado como referência para pobreza absoluta. Adotando o mesmo procedimento metodológico para derivar linhas de pobreza a partir do consumo observado dos mais pobres, pesquisas de orçamentos mais recentes levam a valores mais elevados e, consequentemente, a indicadores mais adversos de pobreza do que os mencionados acima.

\section{3 Índice de GINI}

Importante instrumento para medir o grau de concentração de renda em determinados grupos, este índice aponta a diferença entre os rendimentos dos mais pobres e dos mais ricos. Este índice é largamente usado em diversos estudos relacionados à desenvolvimento econômico, distribuição de renda, bem estar social, pobreza, entre 
outros. Através dele é possível observar que nos últimos anos, a distância que separava os mais ricos na base da pirâmide dos mais pobres caiu no Brasil.

Tabela 09 - Coeficiente de Gini do Estado de Mato Grosso do Sul de 2001 a 2011.

\begin{tabular}{lrrrrrrrrrr}
\hline Ano & 2001 & 2002 & 2003 & 2004 & 2005 & 2006 & 2007 & 2008 & 2009 & 2011 \\
\hline Coefiente de Gini & 0,564 & 0,558 & 0,538 & 0,529 & 0,527 & 0,527 & 0,562 & 0,523 & 0,516 & 0,506 \\
\hline
\end{tabular}

Fonte: Calculado da PNAD

Ao analisar o Índice de Gini o valor zero representa a situação de igualdade total, ou seja, todos teriam a mesma renda. No extremo oposto seria o valor um, ou seja, só uma pessoa detém toda a riqueza. Do período de 2001 a 2011 os valores do Gini em MS não variam significativamente, o que o coloca em situação privilegiada quanto à distribuição de renda da população (Tabela 09).

Tabela 10 - Coeficiente de Gini dos Municípios do estado Mato Grosso do Sul em 1991, 2000 e 2010.

\begin{tabular}{|c|c|c|c|c|c|c|c|}
\hline MUNICÍPIO & 1991 & 2000 & 2010 & MUNICÍPIO & 1991 & 2000 & 2010 \\
\hline ÁGUA CLARA & 0,46 & 0,57 & 0,50 & ITAPORÃ & 0,59 & 0,58 & 0,54 \\
\hline ALCINÓPOLIS & 0,61 & 0,46 & 0,54 & ITAQUIRAÍ & 0,58 & 0,53 & 0,50 \\
\hline AMAMBAI & 0,58 & 0,62 & 0,56 & IVINHEMA & 0,51 & 0,53 & 0,48 \\
\hline ANASTÁCIO & 0,52 & 0,56 & 0,47 & JAPORÃ & 0,52 & 0,54 & 0,66 \\
\hline ANAURILÂNDIA & 0,58 & 0,53 & 0,51 & JARAGUARI & 0,50 & 0,56 & 0,48 \\
\hline ANGÉLICA & 0,50 & 0,49 & 0,42 & JARDIM & 0,61 & 0,67 & 0,55 \\
\hline ANTÔNIO JOÃO & 0,58 & 0,51 & 0,54 & JATEÍ & 0,52 & 0,47 & 0,60 \\
\hline APARECIDA DO TABOADO & 0,55 & 0,52 & 0,46 & JUTI & 0,50 & 0,61 & 0,51 \\
\hline AQUIDAUANA & 0,61 & 0,64 & 0,56 & LADÁRIO & 0,54 & 0,59 & 0,52 \\
\hline ARAL MOREIRA & 0,57 & 0,58 & 0,53 & LAGUNA CARAPÃ & 0,51 & 0,66 & 0,53 \\
\hline BANDEIRANTES & 0,60 & 0,50 & 0,51 & MARACAJU & 0,62 & 0,58 & 0,54 \\
\hline BATAGUASSU & 0,58 & 0,52 & 0,47 & MIRANDA & 0,63 & 0,78 & 0,54 \\
\hline BATAYPORÃ & 0,58 & 0,45 & 0,56 & MUNDO NOVO & 0,56 & 0,53 & 0,50 \\
\hline BELA VISTA & 0,68 & 0,68 & 0,61 & NAVIRAÍ & 0,54 & 0,54 & 0,47 \\
\hline BODOQUENA & 0,51 & 0,58 & 0,50 & NIOAQUE & 0,64 & 0,58 & 0,58 \\
\hline BONITO & 0,58 & 0,60 & 0,54 & NOVA ALVORADA DO SUL & 0,60 & 0,57 & 0,58 \\
\hline BRASILÂNDIA & 0,53 & 0,60 & 0,52 & NOVA ANDRADINA & 0,52 & 0,55 & 0,48 \\
\hline CAARAPÓ & 0,64 & 0,58 & 0,50 & NOVO HORIZONTE DO SUL & 0,51 & 0,51 & 0,40 \\
\hline CAMAPUÃ & 0,57 & 0,56 & 0,49 & PARANAÍBA & 0,60 & 0,62 & 0,49 \\
\hline CAMPO GRANDE & 0,59 & 0,60 & 0,56 & PARANHOS & 0,65 & 0,52 & 0,64 \\
\hline CARACOL & 0,49 & 0,50 & 0,43 & PEDRO GOMES & 0,61 & 0,55 & 0,48 \\
\hline CASSILÂNDIA & 0,65 & 0,53 & 0,54 & PONTA PORÃ & 0,62 & 0,62 & 0,60 \\
\hline CHAPADÃO DO SUL & 0,63 & 0,62 & 0,47 & PORTO MURTINHO & 0,56 & 0,59 & 0,61 \\
\hline CORGUINHO & 0,54 & 0,53 & 0,53 & RIBAS DO RIO PARDO & 0,51 & 0,50 & 0,47 \\
\hline CORONEL SAPUCAIA & 0,51 & 0,54 & 0,55 & RIO BRILHANTE & 0,64 & 0,57 & 0,53 \\
\hline CORUMBÁ & 0,60 & 0,61 & 0,55 & RIO NEGRO & 0,47 & 0,51 & 0,54 \\
\hline COSTA RICA & 0,53 & 0,77 & 0,47 & RIO VERDE MATO GROSSO & 0,55 & 0,55 & 0,46 \\
\hline
\end{tabular}




\begin{tabular}{llllllll} 
COXIM & 0,56 & 0,67 & 0,51 & ROCHEDO & 0,55 & 0,57 & 0,48 \\
DEODÁPOLIS & 0,55 & 0,59 & 0,45 & SANTA RITA DO PARDO & 0,59 & 0,48 & 0,44 \\
DOIS IRMÃOS DO BURITI & 0,53 & 0,59 & 0,58 & SÃO GABRIEL DO OESTE & 0,67 & 0,68 & 0,54 \\
DOURADINA & 0,61 & 0,65 & 0,61 & SETE QUEDAS & 0,54 & 0,63 & 0,54 \\
DOURADOS & 0,58 & 0,61 & 0,52 & SELVÍRIA & 0,59 & 0,53 & 0,44 \\
ELDORADO & 0,57 & 0,52 & 0,49 & SIDROLÂNDIA & 0,59 & 0,64 & 0,57 \\
FÁTIMA DO SUL & 0,60 & 0,57 & 0,52 & SONORA & 0,50 & 0,64 & 0,50 \\
FIGUEIRÃO & 0,53 & 0,48 & 0,44 & TACURU & 0,54 & 0,50 & 0,60 \\
GLÓRIA DE DOURADOS & 0,52 & 0,55 & 0,46 & TAQUARUSSU & 0,59 & 0,51 & 0,42 \\
GUIA LOPES DA LAGUNA & 0,53 & 0,70 & 0,57 & TERENOS & 0,51 & 0,58 & 0,50 \\
IGUATEMI & 0,60 & 0,57 & 0,51 & TRÊS LAGOAS & 0,53 & 0,56 & 0,51 \\
INOCÊNCIA & 0,67 & 0,61 & 0,48 & VICENTINA & 0,42 & 0,60 & 0,46 \\
\hline FOn: AIIAS DO DeSEC
\end{tabular}

Fonte: Atlas do Desenvolvimento Humano no Brasil, 2013.

Segundo o Atlas do Desenvolvimento Humano no Brasil (2013), nos anos 1991 e 2000 dos 78 municípios do estado de MS, 71 apresentaram Índice de Gini maior ou igual a 0,50. Enquanto a média dos municípios brasileiros foi de 0,53. No ano 2000 os municípios de Miranda, Costa Rica e Guia Lopes da Laguna apresentaram índices nos valores 0,78, 0,77 e 0,70 , respectivamente, que são valores melhores do que o do estado de MS (Tabela $10)$.

Segundo Ferreira e Cruz (2008), nesse período, sob o enfoque de clubes de convergência, identificados de forma endógena através de modelo com efeito threshold, evidências empíricas apontam que existiu um processo de convergência da desigualdade da distribuição de renda no Brasil. Sendo que a renda do trabalho mostrou-se mais significante para a redução da desigualdade do que a renda oriunda das transferências governamentais. Além da renda do trabalho, a média dos anos de estudo também contribuiu significativamente para a redução da desigualdade nos municípios, neste período.

Já no ano de 2010 apenas 51 apresentaram índice maior ou igual a 0,50. Os municípios de Novo Horizonte do Sul $(0,40)$, Taquarussu $(0,42)$ e Angélica $(0,42)$, são os que apresentam menor Índice de Gini, ou seja, os que apresentam melhor distribuição de renda. No outro extremo os municípios com os piores Índices de Gini são os municípios de Japorã $(0,66)$, Paranhos $(0,64)$, Bela Vista $(0,61)$, Douradina $(0,61)$ e Porto Murtinho $(0,61)$.

Segundo publicação do programa Avança Brasil (2010), a redução da desigualdade no estado de MS é atribuída à estabilidade econômica propiciada pelo Plano Real, ao eliminar a alta desenfreada dos custos de produção, tornando possível o planejamento de 
longo prazo, fator essencial para o bom desempenho agropecuário e industrial, que gerando emprego e bem-estar social.

Ainda de acordo o Avança Brasil (2010) o Programa de Geração de Emprego e Renda (PROGER), somente no MS criou 1,2 mil empregos diretos e 741 indiretos em 2001, com a aplicação de R\$ 5,2 milhões do Fundo de Amparo ao Trabalhador (FAT), com o objetivo de reduzir a desigualdade social no estado.

Na prática, o Índice de Gini costuma comparar os $20 \%$ mais pobres com os $20 \%$ mais ricos. E na análise da repartição do rendimento é frequente a repartição da população em quintis, ordenando a polução dos mais pobres para os mais ricos e repartindo a população em cinco partes iguais, cada uma com $20 \%$ da população. Cada um destes grupos é um quintil. Na Gráfico 02 tem-se a distribuição dos quintis do estado de MS, onde se observa que no ano de 1991 e 2000 os valores não se alteraram significativamente, mas em 2010 a desigualdade no estado foi reduzida e a curva se desloca para esquerda e para cima.

Gráfico 2 - Distribuição, por quintis, de indivíduos mais pobres segundo a renda domiciliar per capita do Estado de Mato Grosso do Sul, em 1991, 2000 e 2010.

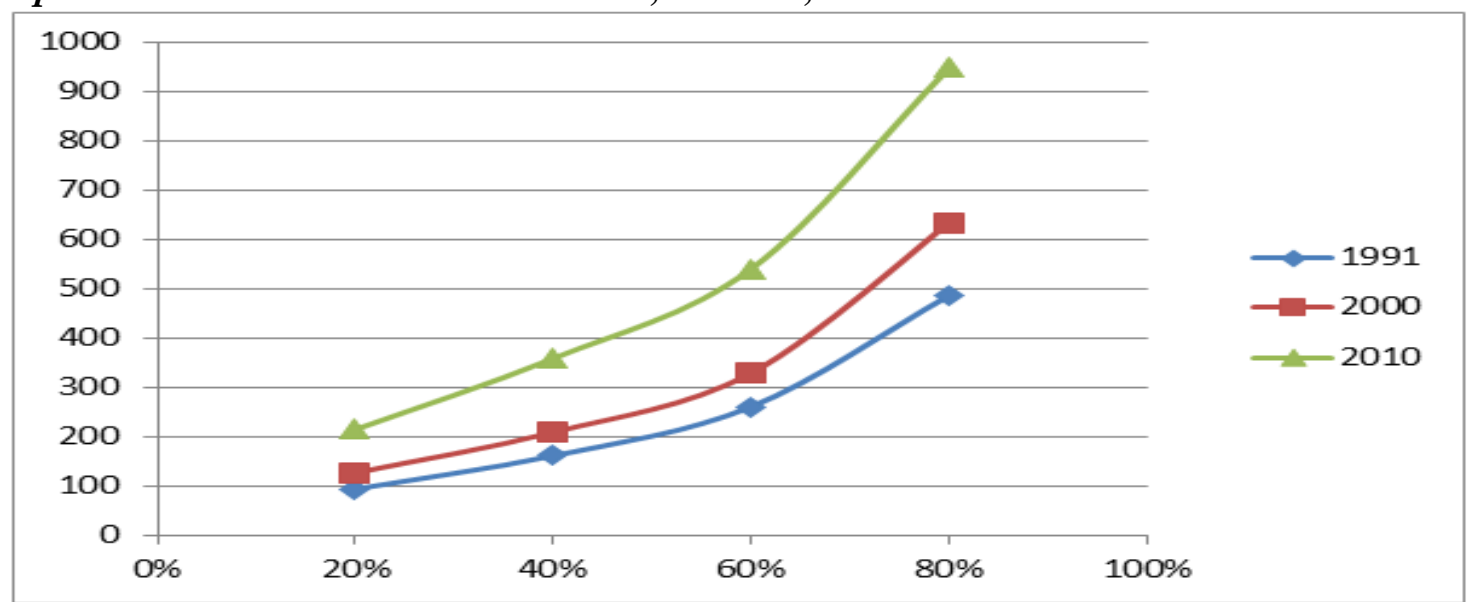

O cálculo do Índice de Gini é baseado na Curva de Lorenz. No eixo X dispõem-se os percentuais acumulados da população, sempre em ordem crescente de renda, e no eixo Y os percentuais acumulados da renda. A Gráfico 03 apresenta as Curva de Lorenz de MS dos anos de 1991, 2000 e 2010.

A área entre a reta de $45^{\circ}$ e a curva é a chamada área de concentração. Se não houvesse concentração, existiria somente a reta de perfeita igualdade. Quanto maior a 
concentração, maior é esta área, a curva que apresenta menor área é a curva de 2010, a que apresenta a menor área é a de 1991.

Gráfico 3 - Curvas de Lorenz de Mato Grosso do Sul, em 1991, 2000 e 2010.

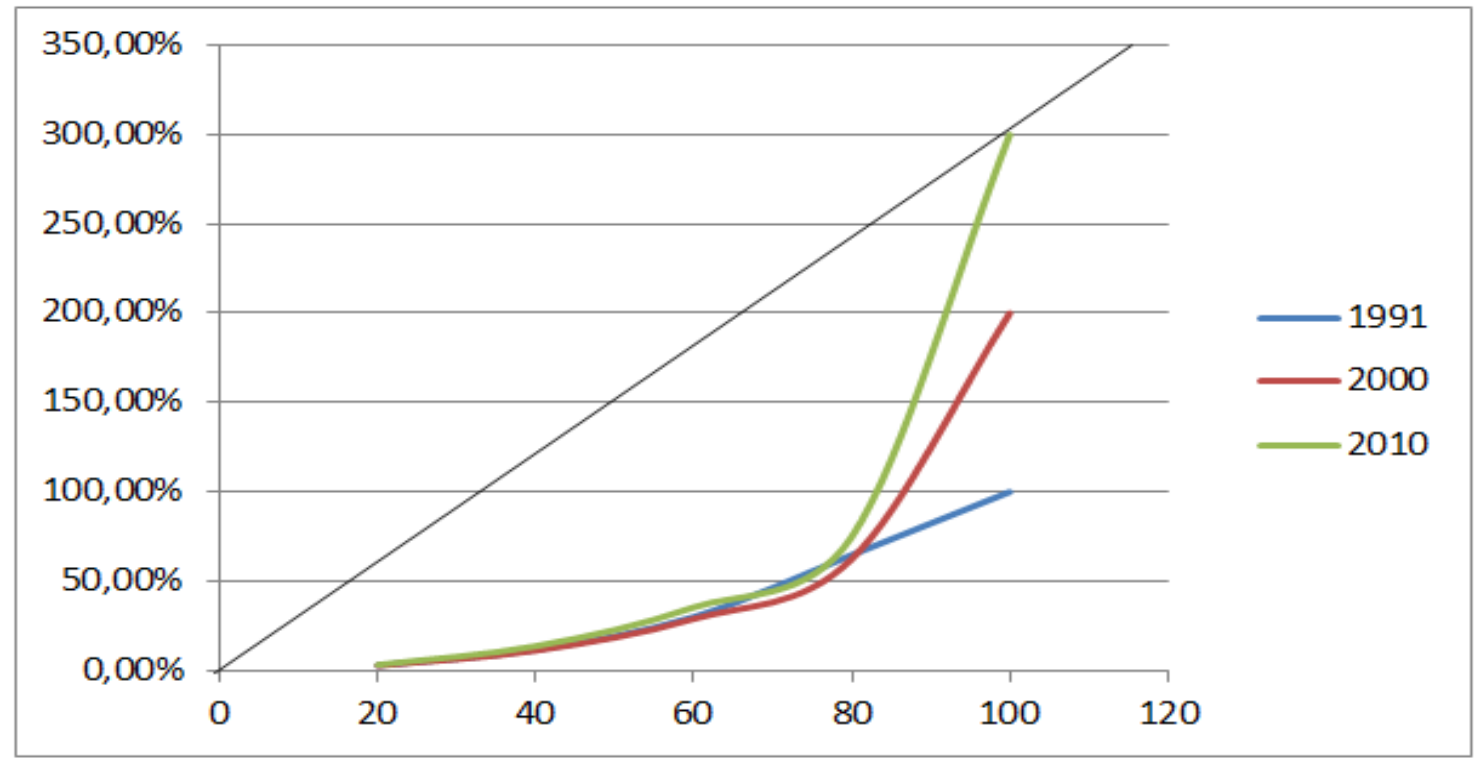

Mato Grosso do Sul reduziu o número de pobres em mais de 40\% entre 1995 e 2008, classificando o estado como $8^{\circ}$ estado com menor número de pessoas em situação de pobreza, mas de acordo com o IPEA (2010), precisa gerar mais empregos e desenvolver melhor seus projetos sociais se quiser erradicar a pobreza até 2016. Por oportuno, segundo projeções do IPEA (2010), no ano de 2016 o estado registraria somente 4\% da população vivendo em estado de pobreza, o que aproximaria a curva de Lorenz da reta de $45^{\circ}$.

\section{Considerações Finais}

Para atingir o objetivo de apresentar os principais indicadores sociais do estado de Mato Grosso do Sul, considerou-se desde os conceitos básicos de desenvolvimento humano e indicadores, bem como os métodos de mensuração da pobreza e desigualdade de renda, destacando as aplicabilidades destes métodos.

Baseado nos dados de 2001 a 2011, da PNAD, Censo Demográfico e Atlas do Desenvolvimento Humano no Brasil, observou-se melhora no acesso a renda e redução na proporção de pobres no estado de Mato Grosso do Sul. Contudo ainda existem pessoas abaixo da linha da pobreza neste estado e muitas em situação de pobreza extrema.

A descentralização, promovida pelo Governo Federal desde 1995, teve reflexo significativo no estado, redistribuindo verbas, atribuições e novos programas sociais expandindo a prática da cidadania. Mas ainda apresenta desafios para melhorar a qualidade 
de vida, necessitando gerar mais empregos e desenvolver melhor pontos como o acesso a educação, ao saneamento básico e água potável, essencial ao combate de causas primárias de doenças sociais, se quiser erradicar a pobreza até 2016.

No Brasil, a utilização de indicadores sociais, configura-se em discussão recente, porém, tornando-se cada vez mais evidente a sua importância para o processo de gestão, isso porque possibilitam informações importantes, permitindo avaliar o passado, o presente e de que forma seguir, em relação aos valores e alcance dos objetivos previamente identificados.

Os dados estatísticos e informações de renda e crescimento econômico são úteis para a construção dos indicadores, na verdade, são matérias-primas para estruturar indicadores. Contudo basear as decisões de gestão em estatísticas públicas, que são simples junções de dados, sem devida contextualização e interpretação dos conceitos operacionalizados, pode-se incorrer no velho erro de desconsiderar a qualidade de vida e o desenvolvimento humano como elemento importante em uma gestão.

\section{Referências Bibliográficas}

ALMEIDA, M. A. B. Qualidade de vida: definição, conceitos e interfaces com outras áreas, de pesquisa. São Paulo: Escola de Artes, Ciências e Humanidades - EACH/USP, 2012.

ATLAS do Desenvolvimento Humano e Condições de vida: Indicadores Brasileiros. PNUD/IPEA/FJP, 2013.

AVANÇA BRASIL. Ações Federais de 1995 a 2002: Mato Grosso do Sul. Disponível em < http://www.abrasil.gov.br/estados/index.htm>, acesso em 18 set. 2013.

BARBOSA, S. R. C. S. Qualidade de Vida e ambiente: uma temática em construção. In: BARBOSA, Sônia Regina da Cal Seixas (org.). A temática ambiental e a pluralidade do Ciclo de Seminários do NEPAM. Campinas: UNICAMP, NEPAM, p. 401-423, 1998.

BORBA, Ana Emília de Oliveira. Proposta de indicadores de sustentabilidade para o setor da construção civil. 2009. Dissertação Mestrado. 134 f. Universidade de Pernambuco, Escola Politécnica, Recife. 2009.

BVS - Biblioteca Virtual em Saúde. Características dos indicadores Socioeconômicos. 2011. Disponível em:

< http://www.ripsa.org.br/fichasIDB/record.php?node=B.5\&lang=pt>, acesso em 11 set. 2013

COSTA, R. D. Principais Índices de Pobreza Brasileira. Revista Eletrônica. Faculdade de Educação, Administração e Tecnologia de IBAITI. Volume 8, 2010. . Disponível em:

$<$ http://www.feati.edu.br/revistaeletronica/downloads/numero1/principaisIndicesPobrezaBrasileira.pdf $>$, acesso em 11 set. 2013 
FERREIRA, R. T.; CRUZ, M. S.. Clubes de Convergência na Desigualdade de Renda nos Municípios Brasileiros. XXXVI Encontro nacional de economia. Associação Nacional dos Centros de Pós-Graduação em Economia (ANPEC). Salvador, Bahia, 2008. Disponível em: <http://www.anpec.org.br/encontro2008/artigos/200807171159380-.pdf>, acesso em 11 set. 2013

HOEHN, John R.; BERGER, Mark C.; BLOMQUIST, Glenn C.. A Hedonic Model of Interregional Wage, Rents, and Amenity Values. Journal of Regional Science 29(4): 605620. 1987.

IPEA-Instituto de Pesquisa Econômica Aplicada. Dimensão, evolução e projeção da pobreza por região e por estado no Brasil. Comunicados do Ipea $\mathrm{N}^{\circ} 58.2010$

IPECE- Instituto de Pesquisa e Estratégia Econômica do Ceará. Entendendo o Índice de GINI. Governo do Estado do Ceará, 2010. Disponível em:

< http://www.ipece.ce.gov.br/publicacoes/Entendendo_Indice_GINI.pdf >, acesso em 11 set. 2013

JANNUZZI, Paulo de Martino. Indicadores sociais no Brasil. Campinas, SP ; Editora Alinea, 2001.

ROCHA, R. M.; MAGALHÃES, A. M. As amenidades naturais influenciam a escolha locacional dos trabalhadores? Evidências para as regiões metropolitanas brasileiras. R. bras. Est. Pop., Rio de Janeiro, v. 28, n. 2, p. 369-387, jul./dez. 2011.

KAHN, M. A revealed preference approach for ranking city quality life. Journal of Urban Economics, v. 38, p. 221-235, 1995.

KNAPP, T. A.; GRAVES, P. E.. "On the Role of Amenities in Models of Migration and Regional Development.” Journal of Regional Science 29(1): 71-87. 1989.

KLIKSBERG, Bernardo. Falácias e mitos do desenvolvimento social. Cortez Editora. São Paulo-SP, 2001.

KIM, Kwang-Koo; MARCOUILLER, David W.; DELLE, Steven C. Natural Amenities and Rural Development: Understanding Spatial and Distributional Attributes. Growth and change: A journal of urban and regional policy. - Lexington, Ky.: University of Kentucky, ISSN 0017-4815, ZDB-ID 2827645. - Vol. 36. 2005, 2, p. 273-297. 2005

MARANS, R.W.; STIMSON, Robert J. Investigating Quality of Urban Life Theory, Methods, and Empirical Research. Social Indicators Research Series, Vol 45. London New York: Springer, 2011.

MARQUES, J. F.; COMUNE, A. Quanto vale o ambiente: interpretações sobre o valor econômico ambiental In: ENCONTRO NACIONAL DE ECONOMIA, 23., Salvador, BA, 12 a 15 de dezembro de 1995, Anais p.633-651. 
MARTINS, G.R. Breve Painel Etno-Hitórico: de Mato Grosso do Sul. Inep. Editora da Universidade Federal de Mato Grosso do Sul. Campo Grande, 2003.

MARZALL, Kátia. Indicadores de sustentabilidade para agroecossistemas. UFRGS, Porto Alegre/RS, Tese

MARZALL, Kátia e ALMEIDA, Jalcione. INDICADORES DE SUSTENTABILIDADE PARA AGROECOSSISTEMAS Estado da arte, limites e potencialidades de uma nova ferramenta para avaliar o desenvolvimento sustentável. Cadernos de Ciência \& Tecnologia, Brasília, v.17, n.1, p.41-59, jan./abr. 2000.

McGRANAHAN, David A., Natural Amenities Drive Rural Population Change. Food and Rural Economics Division, Economic Research Service, U.S. Department of Agriculture. Agricultural Economic Report. No. 781. Washington, 1999.

MELO, L. F. Metrópole, Tecnologia, Amenidades e Riscos. Núcleo de Estudos de População - NEPO/Unicamp. III Encontro da ANPPAS, Brasília - DF, 2006.

MOTTA, R. S.. Manual de valoração econômica de recursos ambientais. Brasília: MMA, 1998.

MINAYO, M. C. S.; HARTZ, Z. M. A.; BUSS, P. M. Qualidade de Vida e saúde: um debate necessário. Ciência \& Saúde Coletiva. Rio de Janeiro, v. 5, n.1, 2000, p. 7-18.

NAHAS, M. I. P. PEREIRA, M. A. M.; ESTEVES, O. A.; GONÇALVES, E. Metodologia de construção do Índice de Qualidade de Vida Urbana dos municípios brasileiros (IQVU-BR). In: XV Encontro Nacional de Estudos Populacionais da Associação Brasileira de Estudos Populacionais., 2006, Caxambu, MG. XV Encontro Nacional de Estudos Populacionais da Associação Brasileira de Estudos Populacionais. 2006.

NEDER, Henrique Dantas. Analise de Indicadores Sociais Utilizando o Stata. Instituto de Economia - Universidade Federal de Uberlandia. 2013. Disponível em < http://www.ecn26.ie.ufu.br/TEXTOS_ESTATISTICA/ANALISE_POLITICAS_SOCIAIS.pdf >, acesso em 11 set. 2013.

PEREIRA, Érico Felden; TEIXEIRA, Clarissa Stefani and SANTOS, Anderlei dos. Qualidade de vida: abordagens, conceitos e avaliação. Rev. bras. educ. fís. esporte [online]. 2012, vol.26, n.2, pp. 241-250. ISSN 1807-5509.

PNUD- Programa das Nações Unidas para o Desenvolvimento. Informe sobre Desarrollo Humano 1996. Ediciones Mundi-Prensa, 1996.

Relatório do Desenvolvimento Humano 2011 Sustentabilidade e Equidade: Um Futuro Melhor para Todos. Plaza, New York, 2011.

Relatório do Desenvolvimento Humano 2013. A Ascensão do Sul: Progresso Humano num Mundo Diversificado. Plaza, New York, 2013. 
REIS, E. J.; MOTTA, R. S. The aplication of economic instruments in environmental policy: the Brazilian Case. Revista Brasileira de Economia, v.. 48, n 4, out./dez. 1994.

ROBACK, J. The value of local urban amenities: theory and measurement. Ph.D. Dissertation, University of Rochester, 1980.

ROCHA, R. M.; Amenidades locais versus oportunidades econômicas: um ranking da qualidade das amenidades para as regiões metropolitanas do Brasil. Associação Nacional dos Centros de Pósgraduação em Economia [ANPEC]. 2007. Disponível em < http://www.anpec.org.br/encontro2007/artigos/A07A118.pdf >, acesso em 18 jun. 2013.

ROCHA, R. M.; MAGALHÃES, A.M. Qualidade das amenidades urbana e a heterogeneidade das preferências: um estudo para as regiões metropolitanas brasileiras. 2010. Disponível em < http://aplicativos.fipe.org.br/enaber/pdf/70.pdf >, acesso em 28 jun 2013.

As amenidades naturais influenciam a escolha locacional dos trabalhadores? Evidências para as regiões metropolitanas brasileiras. Revista brasileira de Estudos de População, Rio de Janeiro, v. 28, n. 2, p. 369-387, jul./dez. 2011.

Valoração das amenidades urbanas: uma estimação a partir dos diferenciais salariais e do custo de habitação para as regiões metropolitanas brasileiras. Rev. econ. contemp. [online]. 2013, vol.17, n.1, pp. 69-98. ISSN 1415-9848. 2013.

ROCHA, Sonia. Pobreza no Brasil. Afinal, do que se trata? 3. ed. Rio de Janeiro: Editora FGV, 2008.

, Sonia. Pobreza no Brasil: A Evolução de Longo Prazo (1970-2011). XXV Fórum Nacional: O Brasil de Amanhã. Transformar Crise em Oportunidade. Rio de Janeiro, 2013.

SANTOS, L. D.;MARTINS I. A qualidade de vida urbana o caso da Cidade do Porto. Working papers da FEP. Porto: Universidade Federal do Porto. Investigação - Trabalhos em curso, $\mathrm{n}^{\mathrm{o}}$ 116, 2002.

SILVEIRA NETO, R. M.; MENEZES, T. A.. Preferência revelada e arbitragem espacial: determinando um ranking de qualidade de vida para as regiões metropolitanas do Brasil. Rev. Bras. Econ. [online]. 2008, vol.62, n.4, pp. 361-380. ISSN 0034-7140.

STEINBERG, M. W. 2000. Making sense of environmental justice. Forum for Applied Research and Public Policy Fall:82.89. 2000.

WEINBERG, A. S. 1998. The environmental justice debate: new agendas for a third generation of research. Society and Natural Resources 11:605. 1998.

WONG, C. Developing indicators to inform local economic development. Urban Studies, 39, 1833-1863. 2002. 
VELEVA, V.; ELLENBECKER, M. A proposal for measuring business sustainability: addressing shortcomings in existing frameworks. University of Massachusetts Lowell, USA. 2000.

YWATA, S. Y., GIROTO, A. P. S., Os Indicadores Sociais como Instrumento de Gestão Social. Serviço Social em Revista. Volume 10 - Número 2. Jan/Jul 2008. Disponível em <http://www.uel.br/revistas/ssrevista/c-v10n2_valderes.htm>, acesso em 18 set. 2013. 